\title{
Water in Sport: Frankston City Council
}

\section{Introduction}

During 2018-2020, Frankston City Council partnered with VicHealth to improve access to water and create healthy drink environments in 9 sports and recreation facilities.

The facilities we worked with included:

$\rightarrow$ Peninsula Aquatic Recreation Centre

$\rightarrow$ Pines Forest Aquatic Centre

$\rightarrow$ Ballam Park Multi Sports Precinct (including Ballam Park Athletics Centre, Karingal Football Netball Club and Karingal Bulls Junior Football Club, Long Island Cricket Club and Peninsula Strikers Junior Soccer Club)

$\rightarrow$ Jubilee Park (Frankston District Netball Association)

$\rightarrow$ Overport Park (Baden Powell Cricket Club)

\section{Objectives}

$\rightarrow$ Increase the promotion and supply of water and reduce the availability and supply of sugary drinks in our community sports and recreation facilities. (>50\% GREEN drinks like water and $<20 \%$ RED sugary drinks)

$\rightarrow$ Strengthen council policies and practices to enable longerterm changes to healthy drinks environments across council-owned sport and recreation facilities.
The Healthy Choices: food and drink classification guide uses a traffic light system to classify foods and drinks as:

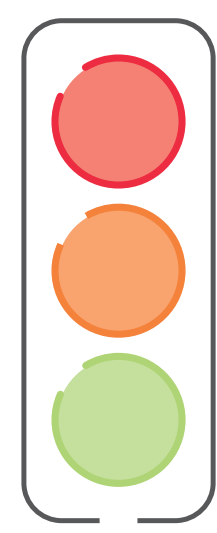

RED: Limit intake

AMBER: Choose carefully

GREEN: Best choice
Why

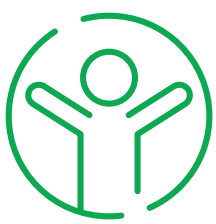

Frankston City Council has a commitment to supporting the health and wellbeing of our community.
The environments in which we live, work, learn, and play are key drivers of the types of food and drink we consume. Local governments can play a key role in implementing policies and practices to improve local food and drink environments.

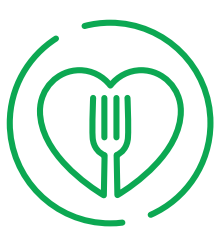

There is community support and expectation for healthy food and drinks $-75 \%$ of customers surveyed from all Water in Sport councils believed that sport and recreation facilities should promote healthy eating. 


\section{Outcomes}

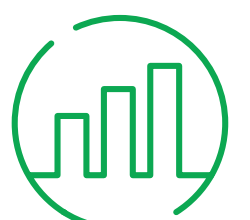

Overall, availability of 'GREEN' drinks increased from $31 \%$ to $61 \%$ of all drinks and 'RED' drinks decreased from $51 \%$ to $17 \%$ of all drinks.

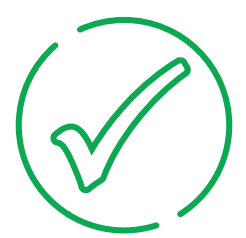

All facilities implemented changes to improve the availability of 'GREEN' drinks and reduce the availability of 'RED' drinks in their retail outlets.

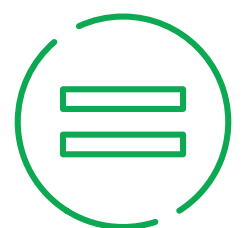

Pines Forest Aquatic Centre had no April 2018 and February 2020.

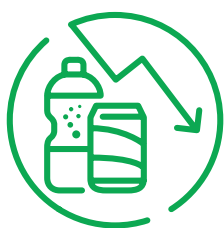

Penninsula Aquatic Recreation Centre sales of 'RED' drinks decreased $11 \%$ between April 2018 and February 2020. change in total drinks revenue between

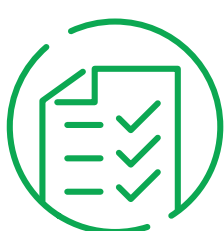

In January 2020, the Frankston Healthy Choices Policy was adopted to support healthy food and drink environments across council owned or managed settings.

\section{Recommendations for creating healthy food retail environments in your community}

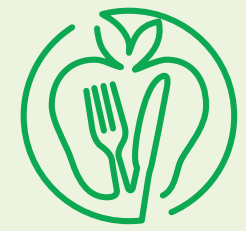

Use the VicHealth toolkit for creating healthy food and drink environments in community

food retail outlets.

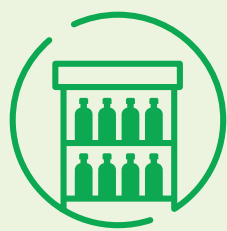

Start by trialing a small 'quick win' which is easy to implement and unlikely to cause revenue loss, such as rearranging the fridge to put 'GREEN' drinks at eye-level.

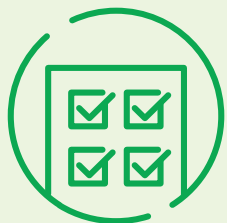

Develop healthy food environment policies and procedures for councils and facilities.

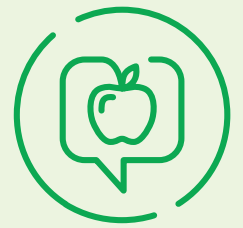

Contact the Healthy Eating Advisory Service for practical implementation support.

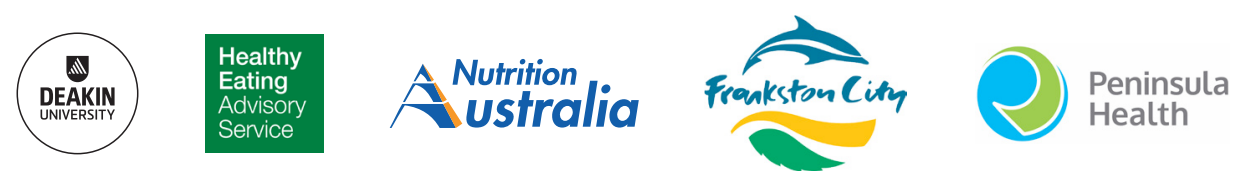

